\title{
Inhibition of Glucocorticoid Secretion by the Hippocampal Formation in the Primate
}

\author{
Robert M. Sapolsky, ${ }^{1}$ Stuart Zola-Morgan, ${ }^{2,3}$ and Larry R. Squire ${ }^{2,3}$ \\ ${ }^{1}$ Department of Biological Sciences, Stanford University, Stanford, California 94305, 2Veterans Affairs Medical Center, San \\ Diego, California 92161, and 'Department of Psychiatry, University of California at San Diego, La Jolla, California 92093
}

\begin{abstract}
Inhibition of the adrenocortical axis by glucocorticoids (GCs) occurs at both hypothalamic and suprahypothalamic sites. In the rat, the hippocampus has been shown to be an essential suprahypothalamic site. The present study shows that the hippocampal system serves a similar role in the nonhuman primate. Bilateral lesions that included the hippocampal formation and the parahippocampal cortex; the hippocampal formation, parahippocampal cortex, and the amygdala; or the fornix all produced GC hypersecretion in cynomolgus monkeys. The hypersecretion occurred throughout the day. Moreover, these lesions were also associated with dexamethasone resistance (i.e., GC hypersecretion following administration of the synthetic GC dexamethasone). The hypersecretion could not be attributed to acute surgical trauma, because neither circumscribed lesions of the amygdala nor conjoint lesions of the perirhinal and parahippocampal cortex produced adrenocortical abnormalities. Finally, in agreement with data derived from the rat, the GC hypersecretion following hippocampal lesions was transient. Secretory activity returned to normal levels by 6-15 months in all operated groups. Thus, the primate hippocampal system appears to share some neuroendocrine functions with the rodent.
\end{abstract}

During stress, glucocorticoids (GCs) are secreted by the adrenal cortex as the final step in a neuroendocrine cascade that begins in the brain. Specifically, stress provokes secretion of corticotropin-releasing hormone (CRF), vasopressin, oxytocin, and other secretagogues into the hypothalamic-pituitary portal circulation. These collectively trigger adrenocorticotropin (ACTH) release by the pituitary, which, in turn, triggers GC secretion. Negative feedback regulation of this cascade by circulating GCs is complex, involving both rapid rate-sensitive and delayed level-sensitive forms of regulation (Keller-Wood and Dallman, 1984). While substantial feedback occurs at the levels of the pituitary and the hypothalamus, suprahypothalamic structures also mediate feedback. For example, the efficacy of GC feedback

\footnotetext{
Received Jan. 24, 1991; revised May 17, 1991; accepted June 4, 1991.

Funding to R.M.S. was provided by NIH grant AGO6633. Support for S.Z.M. and L.R.S. was provided by the Medical Research Service of the Department of Veterans Affairs, NIH Grant NSI9063, The Office of Naval Research, The McKnight Foundation, and a Bioscience Grant for International Joint Research from NEDO, Japan. We thank Cecilia LeClair for her assistance in serum collection, and Drs. Robert Clower and David Amaral for neurohistological analysis of the brains.

Correspondence should be addressed to Robert M. Sapolsky, Department of Biological Sciences, Stanford University, Stanford, CA 94305.

Copyright (C) 1991 Society for Neuroscience $0270-6474 / 91 / 113695-10 \$ 05.00 / 0$
}

inhibition is blunted after hypothalamic deafferentation (Feldman et al., 1973).

In the rat, the hippocampus has been implicated as a suprahypothalamic site mediating GC feedback inhibition. Bilateral lesions of the hippocampus or bilateral transection of the fornix produces hypersecretion of both GCs and ACTH (Fendler et al., 1961; Kim and Kim, 1961; Knigge and Hays, 1963; Moberg et al., 1971; Wilson, 1975; Feldman and Conforti, 1976, 1980; Fischette et al., 1980; Wilson et al., 1980; Kant et al., 1984; Sapolsky et al., 1984; Herman et al., 1989a), hypersecretion of $\mathrm{CRF}$, vasopressin, and oxytocin into the portal circulation (Sapolsky et al., 1989), and increased levels of hypothalamic mRNA for CRF and vasopressin (Herman et al., 1989b). Such hypersecretion can occur under basal nonstressed conditions or can take the form of failure to suppress GC secretion following the administration of exogenous GCs (such as the synthetic GC dexamethasone).

Additional evidence that the hippocampus mediates GC feedback inhibition comes from studies showing that stimulation of the hippocampus in rats inhibits secretion of the hormones of the adrenocortical axis (Endroczi et al., 1959; Dupont et al., 1972; Dunn and Orr, 1984). Furthermore, microimplantation of $\mathrm{GCS}$ into the rat hippocampus inhibits immunostaining of hypothalamic CRF (Kovacs et al., 1986). Finally, microinfusion of corticosteroid receptor antagonists into the hippocampus causes ACTH hypersecretion (Bradbury and Dallman, 1989). This last finding, along with the observation that bilateral hippocampal lesions in rats prevent the inhibitory effects of the synthetic GC dexamethasone on GC secretion (Margarinos et al., 1987), demonstrates that inhibition of the adrenocortical axis by the hippocampal system is accomplished by GC feedback inhibition.

Because of the pathogenic potential of GC hypersecretion, it is important to know if the hippocampal system also regulates the adrenocortical axis in nonhuman primates and in humans. Some correlative evidence suggests this to be the case. Approximately $50 \%$ of individuals with Alzheimer's disease (in which there is typically extensive damage to or isolation of the hippocampal formation) hypersecrete GCs (APA Taskforce, 1987), and those with severe damage to the hippocampal formation (as assessed by CT scan) are more hypersecretory than those with less hippocampal damage (De Leon et al., 1988). More direct evidence of the relationship between the human hippocampus and $\mathrm{GC}$ hypersecretion comes from an early study, carried out during neurosurgery, which reported that stimulation of the hippocampus inhibited adrenocortical secretion (Mandell et al., 1963). Nevertheless, there has been little sys- 
Figure 1. Representative thioninstained coronal sections arranged from rostral (A) to caudal (F) through the temporal lobes showing the extent of damage in one of the nine $\mathrm{H}^{+}$monkeys (monkey $\mathrm{H}^{+} 1$ from Zola-Morgan et al., 1989a). In this monkey, the full rostrocaudal extent of the hippocampus, the dentate gyrus, and the subicular complex was damaged bilaterally. In addition, the lesion encompassed the posterior entorhinal cortex and the parahippocampal cortex bilaterally. The amygdaloid complex (labeled $A$ in $A-$ $C$ ) was intact, as was the rostral half of the entorhinal cortex (labeled $E C$ in $A-$ $C)$. $V$, lateral ventricle. Asterisks in $D$ and $E$ indicate damage produced in the histological processing. Scale bar, 10 $\mathrm{mm}$.
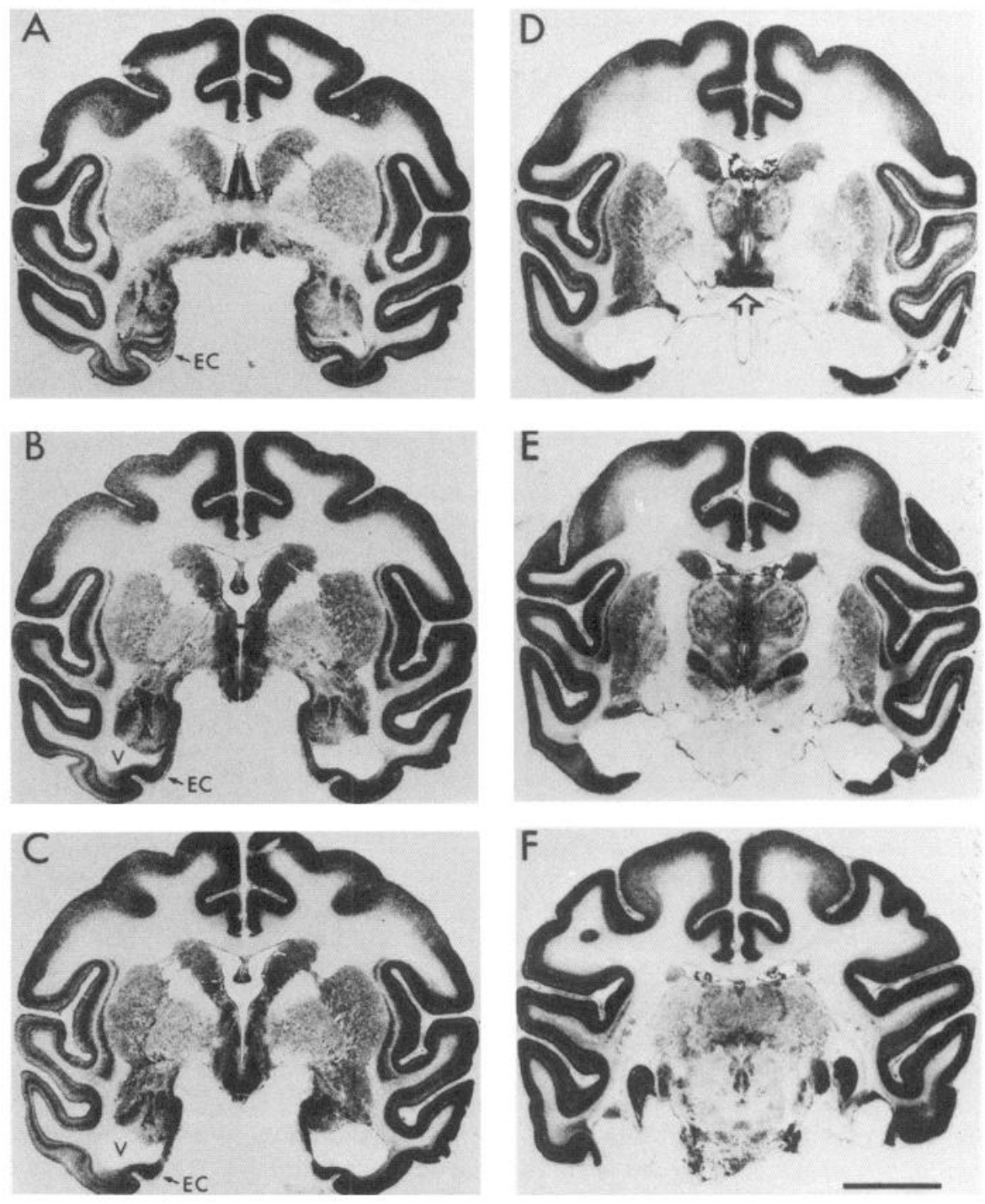

tematic study of the role of the hippocampal system in GC hypersecretion, either in humans or in nonhuman primates. Accordingly, in the present study we examined the role of the hippocampal system as an inhibitor of the adrenocortical axis in the nonhuman primate. Specifically, we examined the effects of damage to the hippocampus, fornix, and other limbic system structures, on circadian GC secretion and on sensitivity to dexamethasone feedback suppression. In addition, because the effects of hippocampal damage on GC secretion in rats have been reported to be transient (Fischette et al., 1980), we investigated whether the effects might also be transient in monkeys.

\section{Materials and Methods}

\section{Subjects}

The findings from 39 cynomolgus monkeys (Macaca fascicularis) will be presented. Based on weight and age tables (Hartley et al., 1984; Szabo and Cowan, 1984), these monkeys were estimated to be 3-6 yr old at the start of the study. All of the monkeys whose data are reported here were also involved in other studies of the effects on memory of damage to the medial temporal lobe of the brain.

Seventeen unoperated control monkeys were studied, together with 22 monkeys in four different operated groups. Of the 17 control mon- keys, 12 were males and 5 were females. No sex differences were observed in the secretion patterns of the control monkeys, and male and female data were therefore pooled in all cases. All the operated monkeys were males, except monkey Fx 2 (see Table 1). In identifying the operated groups in the present report, we adopted the nomenclature used in our previous reports (i.e., for group $\mathrm{H}^{+}, \mathrm{H}$ refers to the hippocampus and ${ }^{+}$refers to adjacent cortex including parahippocampal cortex and posterior entorhinal cortex; for group $\mathrm{A}^{-}, \mathrm{A}$ refers to the amygdala and indicates that the lesions of the amygdala were partial).

\section{Housing}

All monkeys were housed, eight per room, in individual cages that measured 27 cubic feet in volume $(3 \mathrm{ft} \times 3 \mathrm{ft} \times 3 \mathrm{ft})$. Each cage was constructed with a built-in squeeze apparatus so that monkeys could be immobilized momentarily without having to be removed from their home cage. The cage fronts were made of bars spaced 0.5 inch apart. The cages were positioned to provide tactual, visual, and auditory stimulation. That is, each monkey could touch at least one other monkey by reaching through the cage bars, could see at least four other monkeys, and could hear and vocalize with all the other monkeys in the room. Room illumination consisted of overhead fluorescent lighting ( $12 \mathrm{hr}$ on, $12 \mathrm{hr}$ off with lights on at 7 A.M.). Room temperature was maintained at $72-74^{\circ} \mathrm{F}$ and relative humidity was maintained at $50 \%$. Monkeys were fed daily at approximately 4 P.M. with a diet of Purina monkey chow, fruit, and chewable vitamin $\mathrm{C}$ tablets. 

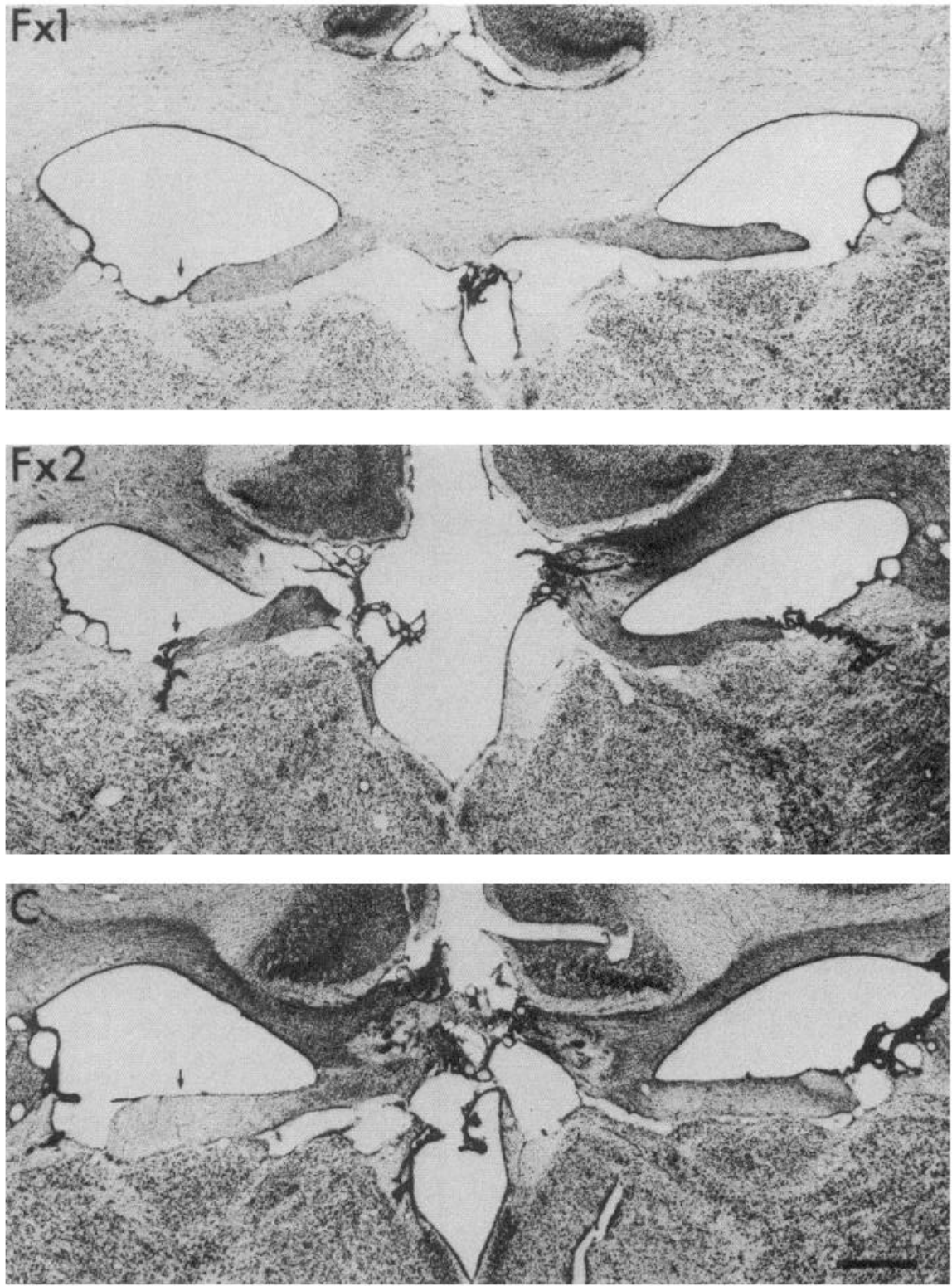

Figure 2. Thionin-stained coronal sections immediately caudal to the fornix transection in two of the six Fx monkeys (Fx1 and Fx 2 from Zola-Morgan et al., 1989a). A control animal (C) with no direct damage to the fornix is also shown. There is marked shrinkage and gliosis of the fornix in the top two panels. Small arrows are placed above the fornix approximately $5 \mathrm{~mm}$ lateral to the midline in each case. Fiber staining distal to the transection in these animals was completely eliminated, indicating a complete transection of the septohippocampal projection (see ZolaMorgan et al., 1989a, for details).

\section{Surgery and neurohistology}

The surgical procedures and detailed neurohistological descriptions of the lesions for all of the operated groups (see Table 1) have been published and will be described only briefly. Lesions were made in a single stage under aseptic conditions. Unless otherwise noted, aspiration lesions were made under direct vision using a stereo microscope. Intravenous sodium pentobarbital $(15-30 \mathrm{mg} / \mathrm{kg}$ ) or isoflurane gas was used for anesthesia. After the lesions were completed and hemostasis achieved, the dura, muscle, and skin were sutured, and antibiotics and analgesics were administered. During the immediate postoperative period, monkeys were placed in a specially designed incubator where their recovery could be continually monitored. They were typically returned to their home cage $24-96 \mathrm{hr}$ after surgery. After completing the studies on memory testing, operated monkeys were killed with an overdose of Nembutal and perfused with $0.9 \%$ saline and $10 \%$ buffered formalin. Frozen sections were cut at $50 \mu \mathrm{m}$, and every fifth section was stained with thionin for Nissl substance.

Group $\mathrm{H}^{+}(\mathrm{n}=9)$. The nine monkeys in this group were drawn from three different memory studies (four monkeys from Zola-Morgan and Squire, 1990; three monkeys from Zola-Morgan et al., 1989a; and two monkeys from R. P. Clower, S. Zola-Morgan, and L. Squire, unpublished observations). The removal in all nine monkeys was intended to include the hippocampus (including the dentate gyrus and the subicular complex) and the cortical regions surrounding the hippocampus (i.e., posterior entorhinal cortex and parahippocampal cortex). Neurohistological analyses have been completed for seven of the monkeys (the remaining two monkeys are currently undergoing additional behavioral testing). In five of the seven monkeys, the lesions were extensive and similar and involved substantial portions ( $80 \%$ or greater) of the hippocampus, the parahippocampal cortex, and posterior entorhinal cortex bilaterally. In the other two monkeys, the lesions were less complete and damaged between $30 \%$ and $50 \%$ of the hippocampus. In one of these monkeys, the lesion damaged nearly all of the parahippocampal cortex bilaterally but involved less than $20 \%$ of the entorhinal cortex bilaterally. In the other monkey, the lesion involved about $50 \%$ of each of the two cortical areas bilaterally.

Figure 1 shows a series of coronal sections through the temporal lobe from one of the nine $\mathrm{H}^{+}$monkeys (monkey $\mathrm{H}^{+} 1$ in Zola-Morgan et al., 1989a). This monkey sustained complete bilateral ablation of the hippocampus including the dentate gyrus and the subicular complex. The posterior portion of the entorhinal cortex was destroyed bilaterally, and the parahippocampal cortex was extensively damaged bilaterally. The perirhinal cortex and the amygdaloid complex were completely spared.

Group Fx $(\mathrm{n}=6)$. In two monkeys, bilateral transection of the fornix (Fx) was accomplished using a direct, neurosurgical approach originally 


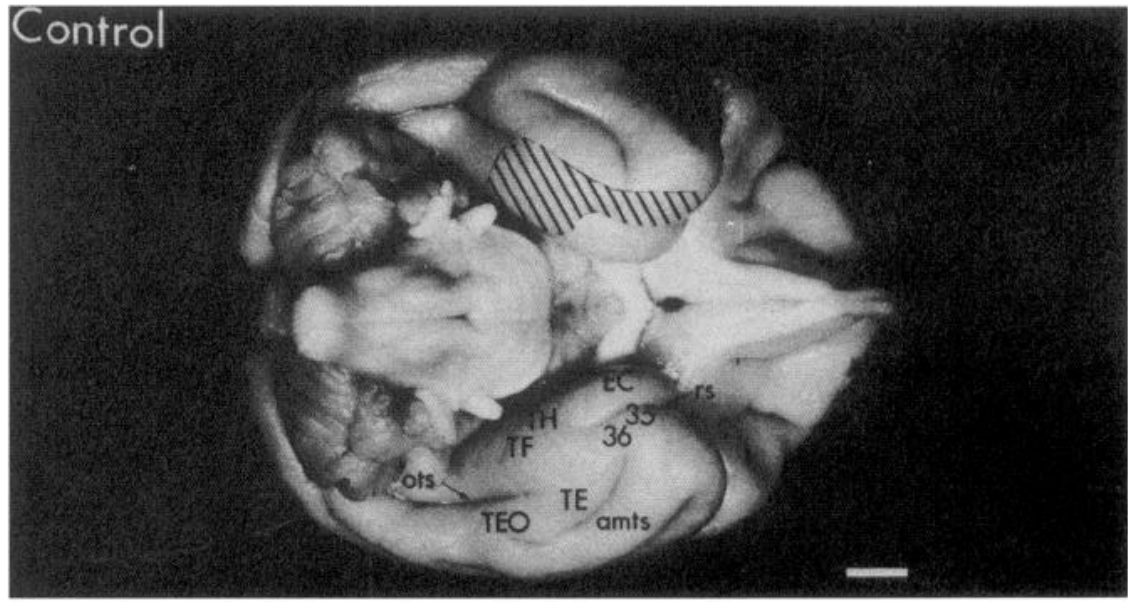

Figure 3. Photographs $(A-D)$ of the ventral surface of the brains of the PRPH monkeys showing the extent of cortical damage (outlined by $d o t s$ ). The top panel shows a normal control brain with the extent of the intended lesion indicated by hatching. The lesions were extensive, although somewhat smaller than intended. Abbreviations: amts, anteromedial temporal sulcus; $E C$, entorhinal cortex; ots, occipitotemporal sulcu; $T F, T H$, parahippocampal cortex; $r s$, rhinal sulcus; 35 and 36 , perirhinal cortex. Scale bar, $5 \mathrm{~mm}$. From Zola-Morgan et al. (1989b).
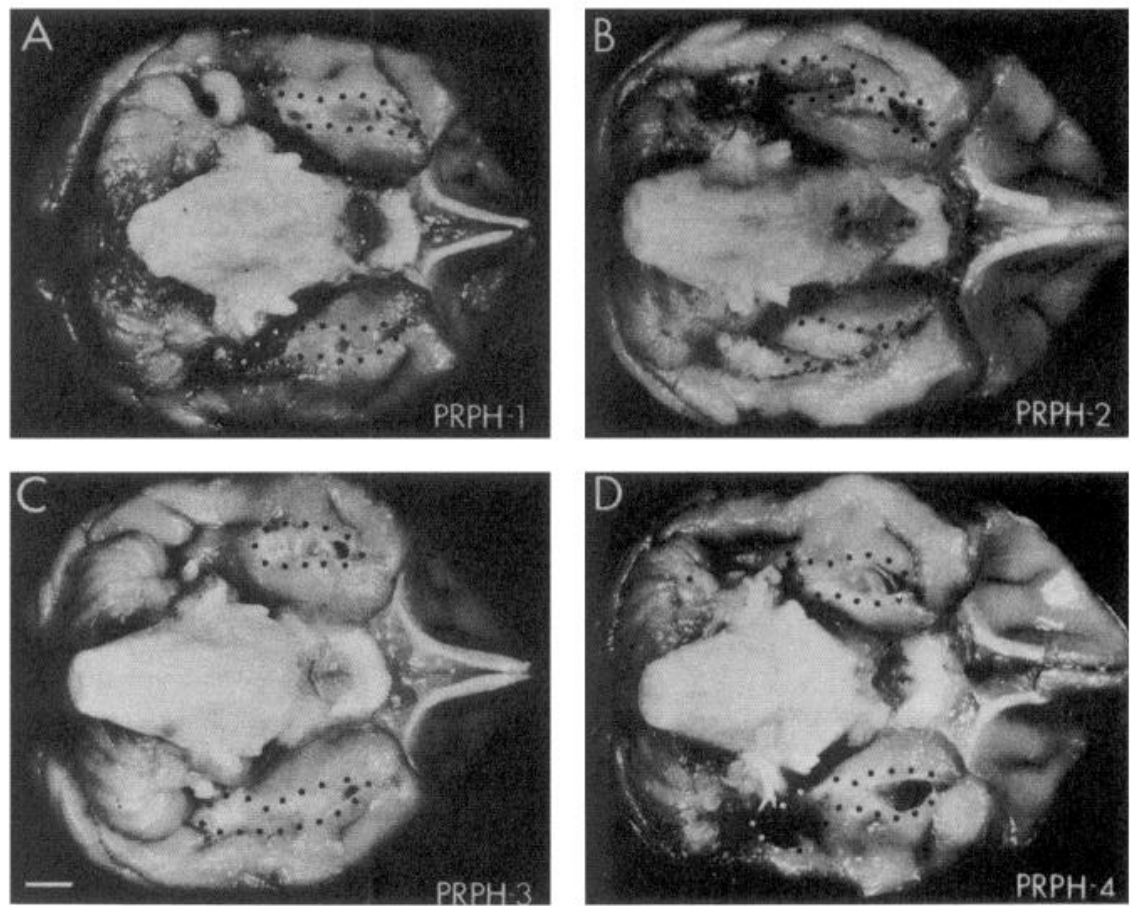

described by Mahut (1972). In four monkeys, a stereotaxic radio frequency procedure was used (Zola-Morgan et al., 1989a). The lesions of the fornix in four of the six monkeys (two prepared by direct surgical approach and two of the four who underwent stereotaxic surgery) were complete bilaterally (Fig. 2; see Zola-Morgan et al., 1989a, for details). Damage to the fornix in the two remaining monkeys in the stereotaxic group was nearly complete bilaterally, except for slight unilateral sparing of the lateral tip in each case.

Group PRPH $(\mathrm{n}=4)$. The intent was to remove the perirhinal (PR) and the parahippocampal (PH) cortex bilaterally. The ablations in three of the four monkeys were extensive and similar; in the fourth monkey the lesion was not as extensive (Fig. 3; see Zola-Morgan et al., 1989b, for details). The most anterior portion of the perirhinal cortex (the temporal polar portion) was largely spared in all cases. The more ventral portion of the perirhinal cortex that lines the rhinal sulcus under the amygdala and adjacent to the entorhinal cortex was nearly completely removed in all cases. The lateral aspect of the parahippocampal cortex (area TF; Bonin and Bailey, 1947) was extensively damaged in all cases, but the ablation damaged the more medially situated area TH (Bonin and Bailey, 1947) in only one case.

Group $A^{-}(\mathrm{n}=3)$. A direct surgical approach was used to damage the amygdala. The amygdaloid lesions in all three animals were incomplete and involved on the average approximately $40-70 \%$ of the amygdaloid complex bilaterally (Fig. 4; see Zola-Morgan et al., 1991, for details).
Each animal also sustained some damage to the surrounding cortical regions (i.e., the perirhinal and entorhinal cortex), but this damage was only moderate (less than $30 \%$ ) and asymmetrical.

\section{Serum collection}

In each housing room, serum was collected from no more than three monkeys at a time, and all designated monkeys within a room were sampled within $3 \mathrm{~min}$ of first entering. Subjects were immobilized in their squeeze cage, and a single drop of blood (approximately $50 \mu \mathrm{l}$ ) was collected by pricking the tail with a lance. The first serum collection always took place at 8 P.M. and was repeated at $6 \mathrm{hr}$ intervals until 8 P.M. the following evening (Fig. 5).

\section{Dexamethasone administration}

At 8 P.M., $24 \mathrm{hr}$ after the first serum collection, dexamethasone (Decadron phosphate; $0.125 \mathrm{mg}$ in $1 \mathrm{ml}$ of saline) was injected intramuscularly in the upper thigh immediately following serum collection. In pilot studies, control monkeys were injected with from 0.063 to $1.0 \mathrm{mg}$ of dexamethasone and monitored for $48 \mathrm{hr}$ thereafter (R. M. Sapolsky and S. Zola-Morgan, unpublished observations). $0.125 \mathrm{mg}$ was found to be the minimal dose that suppressed circulating GC concentrations to below $5 \mu \mathrm{g} / 100 \mathrm{ml}$. Dexamethasone suppression tests were carried 
Table 1. Schedule of postoperative serum collection

\begin{tabular}{llll} 
1-2 months & 6 months & 15 months & 30 months \\
\hline $\mathrm{H}^{+} 1$ & & $\mathrm{H}^{+} 1$ & $\mathrm{H}^{+} 7$ \\
$\mathrm{H}^{+} 2$ & & $\mathrm{H}^{+2}$ & $\mathrm{H}^{+} 8$ \\
$\mathrm{H}^{+} 3$ & $\mathrm{H}^{+3}$ & $\mathrm{H}^{+9}$ \\
$\mathrm{H}^{+} 4$ & & \\
$\mathrm{H}^{+} 5$ & & & \\
$\mathrm{H}^{+} 6$ & & & \\
Fx1 & & & $\mathrm{Fx3}$ \\
Fx2 & $\mathrm{Fx} 1$ & $\mathrm{Fx} 4$ \\
Fx5 & $\mathrm{Fx} 2$ & & \\
Fx6 & & &
\end{tabular}

\section{PRPH 1}

PRPH 2

PRPH 3

PRPH 4

$A^{-1}$

A-2

A-3

This table shows time after surgery that serum was collected from the monkeys in each of the four operated groups. Serum was also collected from 17 unoperated control monkeys (two to four monkeys at each of the five time points). $\mathrm{H}^{+}$, Bilateral lesions of the hippocampus proper, dentate gyrus, subicular complex, posterior entorhinal cortex, and parahippocampal cortex; Fx, bilateral transection of the fornix; PRPH, bilateral conjoint lesions of the perirhinal and parahippocampal cortices; $\mathrm{A}^{-}$, bilateral partial lesions of the amygdaloid complex.

out only with control monkeys and monkeys in the $\mathrm{H}^{+}$, PRPII, and Fx groups.

\section{Radioimmunoassay of cortisol}

Cortisol (the species-typical GC of primates and humans) was measured by radioimmunoassay, using antibody F $21-53$ (Endocrine Sciences, Tarzana, CA) by methods published previously (Krey et al., 1975). Coefficients of variation within and between assays were less than $11 \%(n$ $=12$ ). Samples from ablated and normal subjects were run in the same assay.

\section{Experimental design and statistical analysis}

Table 1 shows the schedule of postoperative serum collection for the monkeys in the four operated groups. Most of the operated monkeys were sampled at only one of the indicated time points. The exceptions were three $\mathrm{H}^{+}$monkeys, who were tested on two occasions separated by 13 months, and two Fx monkeys, who were tested on two occasions separated by 4 months. Thus, of the 22 operated monkeys, 17 were tested on one occasion, and 5 were tested on two occasions. Because the majority of the cases did not involve repeated measures, and because analysis of variance for nonrepeated measures is a more conservative statistical test, all of the statistical analyses reported here were carried out as if each monkey were studied on only one occasion. We thank Professor A. Adikhari of Stanford University for advice on statistical analysis of the data.

\section{Results}

Circadian secretion of cortisol. Cortisol hypersecretion was observed in the $\mathrm{H}^{+}$and $\mathrm{Fx}$ groups when monkeys were sampled within 2 months after surgery. Hyperseceretory levels were not significantly different in the $\mathrm{H}^{+}$and $\mathrm{Fx}$ groups [mean cortisol values $(\mu \mathrm{g} / 100 \mathrm{ml})$ across the $24 \mathrm{hr}$ sampling period: $\mathrm{H}^{+}=37$ \pm 9 , Fx $=26 \pm 5 ; p>0.10$ ]. The data from the monkeys in both groups were therefore combined $\left(\mathrm{H}^{+} / \mathrm{Fx}\right.$ group). Figure $5 \mathrm{~A}$ shows that cortisol concentrations in the combined $\mathrm{H}^{+} / \mathrm{Fx}$ group were highly elevated throughout the $24 \mathrm{hr}$ sampling period (all $p$ values $<0.01$ ), with the exception of the 2 A.M. time point
Table 2. Time course of recovery from hypercortisolism

\begin{tabular}{lll} 
Time after surgery & Circadian secretion & $\begin{array}{l}\text { Dexamethasone } \\
\text { secretion }\end{array}$ \\
\hline $\begin{array}{l}\text { I. } \mathrm{H}^{+} \text {lesion } \\
2 \text { months }\end{array}$ & $39 \pm 4^{*}$ \\
15 months & $15 \pm 3$ & $18 \pm 2$ \\
30 months & $15 \pm 4$ & \\
II. Fx lesion & $38 \pm 4^{*}$ & \\
2 months & $4 \pm 0.5^{* *}$ & \\
6 months & $8 \pm 1^{* *}$ & $16 \pm 2$ \\
30 months & $16 \pm 2$ & \\
III. PR PH lesion & & \\
2 months & $16 \pm 1$ & $16 \pm 5$ \\
IV. A- lesion & $18 \pm 5$ & \\
2 months & & \\
V. Unoperated controls & &
\end{tabular}

Mean circadian secretion ( \pm SEM) is expressed as $\mu \mathrm{g}$ of cortisol $/ 100 \mathrm{ml} / 24 \mathrm{hr}$. Dexamethasone data are expressed as $\mu \mathrm{g}$ of cortisol/100 ml/48 hr. *, Values significantly greater than control values, $p<0.001 ;{ }^{* *}$, values significantly lower than control values, $p<0.05$.

$(p>0.10)$. A two-way ANOVA revealed a significant group effect $[F(1,125)=25.5 ; p<0.001]$.

Figure $5 B$ summarizes the data in Figure $5 A$ by representing the areas under the two curves as vertical bars. Cortisol concentrations for the PRPH and $\mathrm{A}^{-}$groups are also shown. Samples were obtained from these two groups at the same postoperative times as for the $\mathrm{H}^{+} / \mathrm{Fx}$ group. The $\mathrm{H}^{+} / \mathrm{Fx}$ group evidenced a higher overall cortisol concentration than any of the other groups (all $p$ values $<0.001$ ). Moreover, the overall cortisol concentrations for the PRPH and the $\mathrm{A}^{-}$groups did not differ from each other or from that of the control value ( $p$ values $>$ 0.10 ). Thus, the postoperative hypersecretion of cortisol observed in the $\mathrm{H}^{+} / \mathrm{Fx}$ group during the 2 months following surgery cannot be due to acute trauma related to surgery.

Sensitivity to dexamethasone. Twenty-four hours after the first serum collection, monkeys in the $\mathrm{H}^{+}$group and unoperated control monkeys were administered the synthetic GC dexamethasone (monkcys in thc Fx group were not given dexamethasone; Table 2). Serum samples were then obtained at 6 $\mathrm{hr}$ intervals over the next $48 \mathrm{hr}$ (Fig. 6 $\mathrm{A}$ ). A two-way ANOVA revealed significant effects of group $[F(1,82)=30.2 ; p<0.001]$ and time $[F(6,82)=4.7 ; p<0.001]$. Additional analyses showed that in the control monkeys cortisol concentrations were significantly suppressed for at least $12 \mathrm{hr}$ after dexamethasone administration (Fig. 6A). In contrast, monkeys in the $\mathrm{H}^{+}$group were dexamethasone resistant; that is, cortisol levels were significantly suppressed for only $6 \mathrm{hr}$. Moreover, at three of the six post-dexamethasone time points, the $\mathrm{H}^{+}$group exhibited higher levels of cortisol secretion than did the unoperated control group ( $p$ values $<0.05$ for all five time points).

Figure $6 B$ summarizes the data from the control and $\mathrm{H}^{+}$groups in Figure $6 \mathrm{~A}$. The vertical bars represent the areas under the group curves for dexamethasone responsiveness. Responsiveness of the PRPH group to dexamethasone is also shown. Samples were obtained from the PRPH group at the same postoperative time interval and at the same post-dexamethasone time points as for the control and the $\mathrm{H}^{+}$groups. The $\mathrm{H}^{+}$group evidenced a higher overall cortisol concentration than either the control group or the PRPH group ( $p$ values $<0.001$ ). Moreover, 

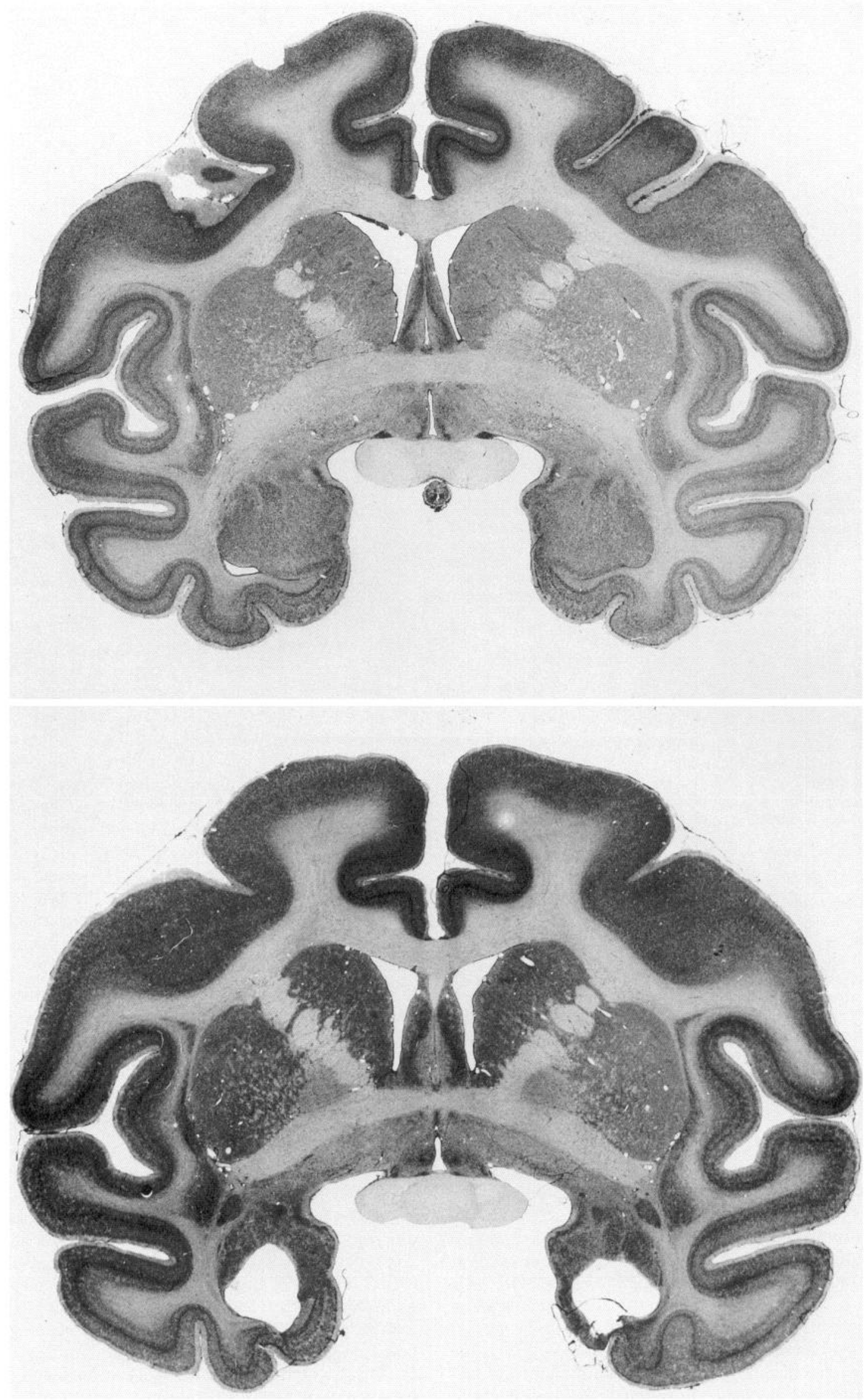

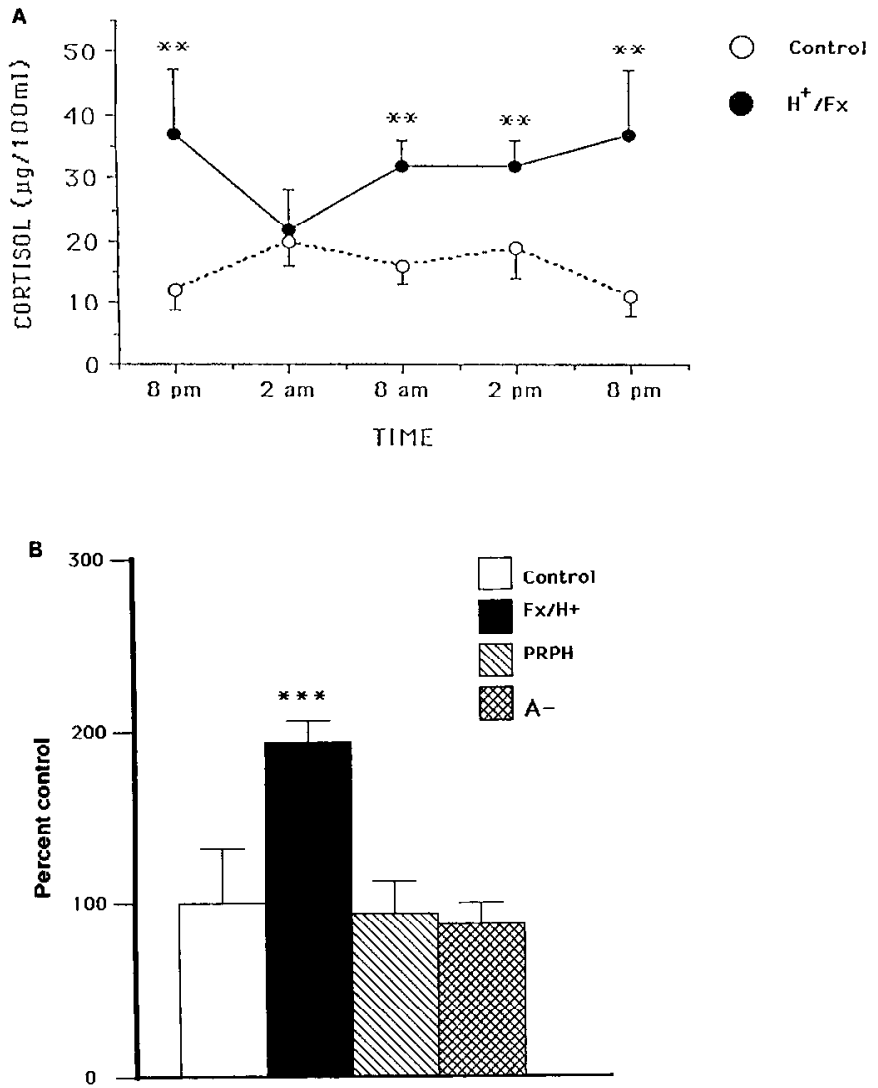

Figure 5. A, Circulating cortisol concentrations $(\mu \mathrm{g} / 100 \mathrm{ml})$ for control monkeys (open circles) and monkeys from $\mathrm{H}^{+}$or Fx groups (solid circles). $B$, The vertical bars represent the area under the curve of basal cortisol secretion (expressed as percentage of control values; micrograms of cortisol secreted $/ 100 \mathrm{ml} / 24 \mathrm{hr}$ ) for the indicated operated groups. The data are derived from Figure $5 A .{ }^{* *}, p<0.001$, comparing operated and control groups.

the overall cortisol concentrations of the PRPH group did not differ from that of the unoperated control group $(p>0.10)$. Thus, the postoperative dexamethasone resistance observed in the $\mathrm{H}^{+}$group was not likely a result of acute trauma related to surgery, as monkeys in the PRPH group responded to dexamethasone in the same way as control monkeys.

Figure 7 shows that, for the nine $\mathrm{H}^{+}$monkeys, there was a significant correlation between postoperative basal cortisol levels and postoperative cortisol levels following administration of dexamethasone $(r=0.93, p<0.001)$. Specifically, operated monkeys who exhibited the highest basal hypersecretory levels were also the most dexamethasone resistant. This relationship was not observed in the unoperated monkeys $(n=9 ; r=0.17$; $p>0.50$ ).

The hypersecretion of cortisol observed in the $\mathrm{H}^{+}$and $\mathrm{Fx}$ groups at 2 months after surgery was not permanent (Table 2). By 15 months after surgery, basal cortisol levels in monkeys in the $\mathrm{H}^{+}$group were not different from those observed in the unoperated control monkeys $(p>0.10)$. A different pattern emerged for the monkeys in the Fx group. By 6 months after
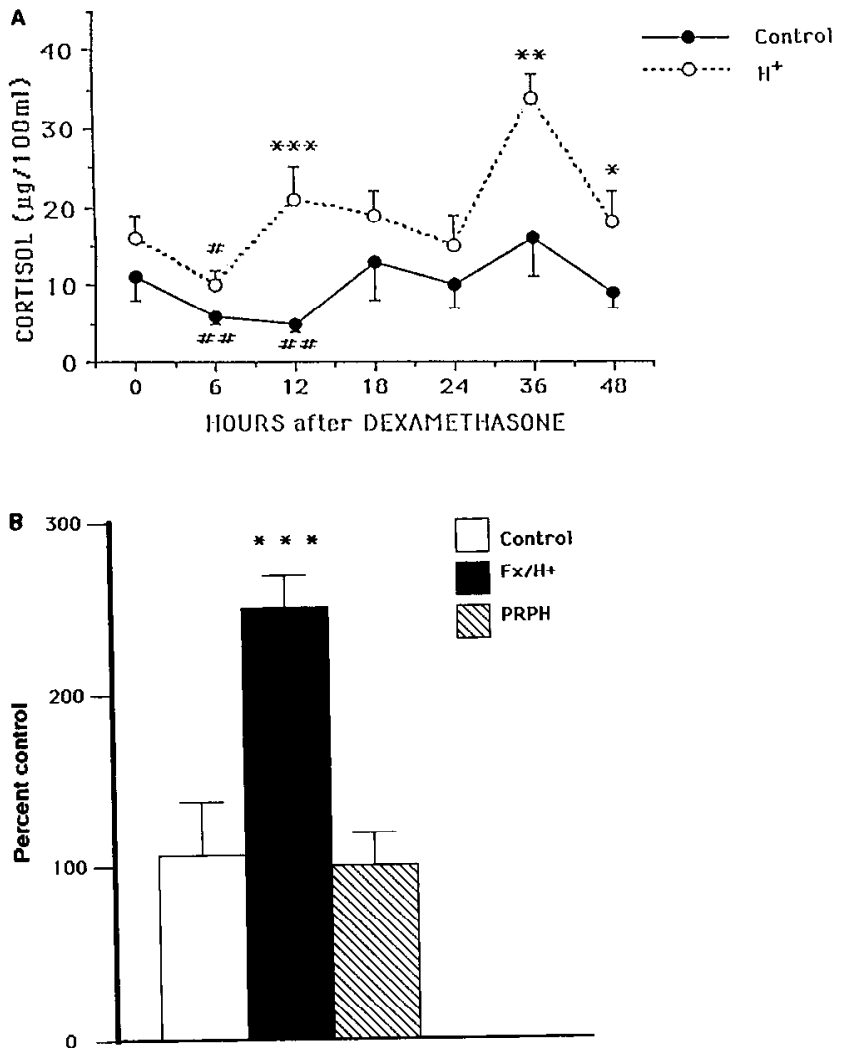

Figure 6. A, Cortisol secretion $(\mu \mathrm{g} / 100 \mathrm{ml})$ following the administration of dexamethasone to unoperated control monkeys (solid circles) and monkeys in the $\mathrm{H}^{+}$group (open circles). ${ }^{* *}$ indicates $p<0.02$, comparing each time point to pre-dexamethasone values for that group; $*, * *$, and ${ }^{* * *}$ indicate $p<0.05,0.01$, and 0.001 , respectively, comparing control and operated monkeys at each time point. $B$, Area under the curve of cortisol secretion following dexamethasone administration (expressed as percentage of control; micrograms of cortisol secreted $/ 100$ $\mathrm{ml} / 48 \mathrm{hr}$ ); data are derived from Figure $6 A .^{* * *}, p<0.001$.

surgery, basal cortisol levels in the Fx monkeys were significantly lower than those observed in the unoperated control monkeys $(p<0.01)$, and they remained lower for 30 months after surgery (the longest postoperative time point sampled).

\section{Discussion}

In the rodent, the hippocampal system can inhibit the adrenocortical axis. The earliest demonstrations of this inhibition predated radioimmunoassays for GCs (Kim and Kim, 1961). As assay methods improved, however, studies demonstrated inhibition of GCs and ACTH by the hippocampus (Moberg et al., 1971; Wilson, 1975; Feldman and Conforti, 1976, 1980; Fischette et al., 1980; Wilson et al., 1980; Dunn et al., 1984; Kant et al., 1984; Sapolsky et al., 1984; Kovacs et al., 1986; Herman et al., 1989a). Recently, the hippocampal system has also been shown to inhibit hypothalamic mRNA or actual portal concentrations of the hypothalamic secretagogues (Herman et al., 1989b; Sapolsky et al., 1989).

A considerable amount has been learned about the nature of

Figure 4. A thionin-stained coronal section through the temporal lobes in a normal monkey (top) and in one of the three $\mathrm{A}^{-}$monkeys (bottom; monkey A-2 in Zola-Morgan et al., 1990). The lesion in this monkey was ventral and small, involving mainly the basal nucleus (which suffered severe bilateral damage) and the lateral nucleus (which suffered moderate bilateral damage). Periamygdaloid cortex was entirely spared bilaterally. In the section shown, the entorhinal cortex was damaged on the right side, but there was almost no entorhinal damage on the left side. 


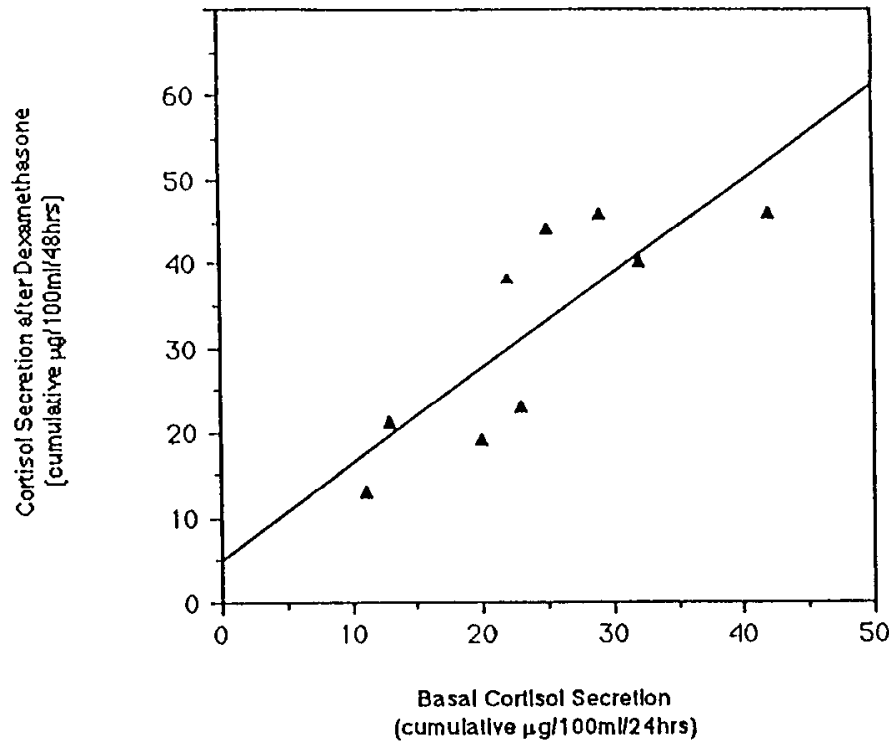

Figure 7. Correlation between basal cortisol secretion (cumulative cortisol secretion in $\mu \mathrm{g} / 100 \mathrm{ml} / 24 \mathrm{hr}$ ) and cumulative cortisol secretion following dexamethasone (cumulative secretion in $\mu \mathrm{g} / 100 \mathrm{ml} / 48 \mathrm{hr}$ ) for the nine $\mathrm{H}^{+}$monkeys monitored 2 and 15 months after surgery. Correlation coefficient $(r)$ was $0.93 ; p<0.001$.

this inhibition. The hippocampal-fornix system appears to exert its inhibitory role via fibers from the fornix that project to the bed nucleus, which, in turn, projects to the vicinity of the paraventricular nucleus (Herman et al., 1989b). Both high-affinity type I and lower-affinity type II corticosteroid receptors in the hippocampus appear to mediate GC feedback inhibition (Bradbury and Dallman, 1989; Dallman et al., 1987; Sapolsky et al., 1990). The hippocampus can inhibit secretion of the hypothalamic ACTH secretagogues CRF, oxytocin, and vasopressin, and it can differentially regulate each secretagogue (Sapolsky et al., 1989). Finally, it appears that if the number of corticosteroid receptors in the hippocampus is reduced (due to stress-induced downregulation of such receptors), the efficacy with which the hippocampus mediates GC feedback inhibition declines (Sapolsky et al., 1984).

In contrast to the numerous studies in rodents, few studies have examined whether the hippocampal system plays a similar role in the primate. If the hippocampal system in primates did have an inhibitory role with respect to neuroendocrine activity, it could help clarify our understanding of reported instances of hypercortisolism in humans. For example, hypercortisolism and dexamethasone resistance are observed in humans with Alzheimer's disease in which there is preferential hippocampal system damage (APA Taskforce, 1987), and in extreme old age (reviewed in Sapolsky, 1989) in which there is normative loss of hippocampal system neurons (Coleman and Flood, 1987). An understanding of the neuroendocrine role of the primate hippocampus would set the stage for asking why only some aged subjects and patients with Alzheimer's disease are hypersecretory.

The present study examined the role played by the hippocampal system in neuroendocrine regulation in the nonhuman primate. Our data strongly suggcst that the primate hippocampus inhibits the adrenocortical axis. Monkeys in the $\mathrm{H}^{+}$and Fx groups hypersecreted cortisol for up to 2 months following surgery. This finding agrees with the results of an earlier study showing that stimulation of the human hippocampus (during neurosurgery) inhibited adrenocortical activity (Mandell et al., 1963). These findings cast light on some, but not all, of the following issues:

(1) In both rats and humans, chronic stress causes GC hypersecretion and resistance to feedback regulation (Sapolsky et al., 1984; Baumgartner et al., 1985; Ceulemans et al., 1985; Dallman et al., 1987). The hypersecretion observed in the $\mathrm{H}^{+}$ and Fx monkeys was not due to the acute stress associated with neurosurgery. Monkeys in the PRPH and $\mathrm{A}^{-}$groups were tested at the same intervals after surgery as the monkeys in the $\mathrm{H}^{+}$and Fx groups, but they were not hypersecretory.

(2) Monkeys in the PRPH group sustained substantial bilateral damage to perirhinal cortex and parahippocampal cortex. These two cortical regions provide nearly two-thirds of the cortical input to the hippocampal formation, specifically the entorhinal cortex (Insausti et al., 1987). Nevertheless, monkeys in the PRPH group did not exhibit cortisol hypersecretion. Thus, even when partially deafferented, the hippocampus can inhibit neuroendocrine activity along the adrenocortical axis.

(3) It is not clear when in the circadian cycle the primate hippocampus inhibits GC secretion. In the rodent, the inhibitory role for the hippocampal system is strongest during the circadian trough (Moberg et al., 1971; Fischette et al., 1980). This implies that the strength and site of feedback regulation vary during the day (Dallman et al., 1987). Superficially, the primate appears to be different, insofar as GC sccretion of monkeys in the $\mathrm{H}^{+}$ and Fx groups was elevated throughout the $24 \mathrm{hr}$ sampling period except at 2 A.M. However, there was not a statistically significant circadian cycle in the control monkeys (i.e., 8 A.M. and 8 P.M. values only approached being significantly different in individuals by paired $t$ test, $p<0.10$ ), limiting any evaluation of the circadian role of the hippocampal system in the primate. As a probable cause of the weak circadian trend, all subjects were fed once per day in the afternoon, which is known to entrain GC secretion to the feeding rhythm, rather than the circadian rhythm (reviewed in Dallman et al., 1987). Such a feeding pattern also represents a mild stressor and elevates basal GC concentrations. This probably explains the relatively high basal concentrations in control monkeys and suggests that they more appropriately represent mild stress values. Thus, quantitative comparison of these data should be done with rodent data derived from studies examining the effects of hippocampal system lesions upon stress-induced GC secretion (cf. Fendler et al., 1961; Knigge and Hays, 1963; Feldman and Conforti, 1980; Wilson et al., 1980; Sapolsky et al., 1984).

(4) Monkeys in the $\mathrm{H}^{+}$group were dexamethasone resistant; that is, after treatment with dexamethasone, their cortisol levels increased (escaped from suppression) sooner than did cortisol levels in unoperated monkeys. This replicates findings in the rodent; moreover, a similar pattern of dexamethasone resistance occurs in Alzheimer's disease (APA Taskforce, 1987). However, it is not clear if this represents a lesion-induced loss of a feedback site in the hippocampal system. Alternatively, damage to that system could enhance stimulation of the adrenocortical axis (i.e., the basal hypersecretion), and dexamethasone might simply act at a different point in the axis to reduce the degree of that stimulation in proportion to the magnitude of the dexamethasonc signal. The close agreement between the extent of basal hypersecretion in $\mathrm{H}^{+}$monkeys (Fig. 7, x-axis) and the extent of dexamethasone resistance (Fig. 7, y-axis) supports the latter possibility, although a larger sample size and a broader range 
of dexamethasone doses are needed for greater certainty about that conclusion.

(5) The hypercortisolism that followed hippocampal lesions in monkeys was transient. By 15 months after surgery, monkeys in the $\mathrm{H}^{+}$group exhibited secretory activity within the normal range. Similarly, the corticosterone hypersecretion that follows hippocampal system lesion in rodents is not permanent (Fischette et al., 1980). Whether recovery represents other neural structures taking on a stronger inhibitory role, altered pituitary sensitivity to secretagogues, or altered adrenal responsiveness to ACTH remains to be determined. Evidence for plasticity at all of these levels has been obtained in studies in rodents (Sapolsky and Plotsky, 1990). With respect to the clinical relevance of such recovery, if there are cases of Alzheimer's disease where the extent of hippocampal damage remains stable for a period of time, there could be some recovery of normal adrenocortical regulation (reviewed in Sapolsky and Plotsky, 1990). This possibility of recovery of cortisol concentration over time makes it difficult to evaluate one additional study of cortisol secretion in primates with hippocampal lesions (Regestein et al., 1986) in which secretion during cognitive and/or stressful tasks was reported to diminish. Unfortunately, no information was provided with respect to the interval between surgery and study.

(6) While the hypercortisolism that followed bilateral transection of the fornix was also not enduring, the pattern differed from that observed in monkeys with $\mathrm{H}^{+}$lesions. Whereas the secretory lcvels of the $\mathrm{H}^{+}$monkeys eventually returned to normal, the Fx monkeys eventually became hyposecretory. That is, by 6 months after surgery, the basal secretion of monkeys with Fx lesions was significantly below normal levels. In a separate group of monkeys with Fx lesions, this hypocortisolism lasted as long as 30 months (Table 2) (it should be noted that GC values from control monkeys studied at those times did not differ from values for other control monkeys, as tested by twoway ANOVA). The finding has not been reported in rodents (Fischette et al., 1980), and its cause in primates is not clear. Potentially, it may represent shifting strengths of regulation by other points in the adrenocortical axis. Alternatively, it may arise because Fx monkeys habituate to the mild stressor of oncea-day feeding (see above), whereas other subjects do not.

In conclusion, considerable literature suggests that the hippocampus inhibits GC secretion in the rodent. The present data are among the first to suggest a similar role for the hippocampus in the primate.

\section{References}

APA Taskforce on Laboratory Tests in Psychiatry (1987) The dexamethasone suppression test: an overview of its current status in psychiatry. Am J Psychiatry 144:1253-1262.

Baumgartner A, Graf K, Kurten I (1985) The dexamethasone suppression test in depression, schizophrenia and during experimental stress. Biol Psychiatry 20:675-682.

Bonin G, Bailey P (1947) The neocortex of Macaca mulatta. Urbana, IL: University of Illinois.

Bradbury M, Dallman M (1989) Effects of hippocampal type I and type II glucocorticoid receptor antagonists on ACTH levels in the PM. Soc Neurosci Abstr 15:290.4.

Ceulemans D, Westenberg H, van Praag H (1985) The effect of stress on the dexamethasone suppression test. Psychiatry Res 14:189-197.

Coleman P, Flood D (1987) Neuron numbers and dendritic extent in normal aging and Alzheimer's disease. Neurobiol Aging 8:521-536.

Dallman M, Akana S, Cascio C, Darlington D, Jacobson L, Levin N (1987) Regulation of ACTH secretion: variations on a theme of $B$. Rec Prog Horm Res 43:113-173.

De Leon M, McRae T, Tsai J, George A, Marcus D, Freedman M, Wolf
A, McEwen B (1988) Abnormal cortisol response in Alzheimer's disease linked to hippocampal atrophy. Lancet 2:391-392.

Dunn J, Orr S (1984) Differential plasma corticosterone responses to hippocampal stimulation. Exp Brain Res 54:1-11.

Dupont R, Bastarache E, Endroczi F, Fortier C (1972) Hippocampal stimulation on plasma thyrotropin and corticosterone responses to acute cold-exposure in rat. Can J Physiol Pharmacol 50:364-369.

Endroczi E, Lissak K, Bohus B (1959) The inhibitory influence of archicortical structures on pituitary adrenal function. Acta Physiol Acad Sci Hung 16:17-24.

Feldman S, Conforti N (1976) Feedback effects of dexamethasone on adrenocortical responses of rats with fornix section. Horm Res 7:5659.

Feldman S, Conforti N (1980) Participation of the dorsal hippocampus in the glucocorticoid feedback effect on adrenocortical activity. Neuroendocrinology 30:52 56 .

Feldman S, Chowers I, Conforti N (1973) Effect of dexamethasone on adrenocortical response in intact and hypothalamic deafferented rats. Acta Endocrinol (Copenh) 73:660-666.

Fendler K, Karmos G, Telegdy M (1961) The effect of hippocampal lesion on pituitary-adrenal function. Acta Physiol Scand 20:293-301.

Fischette C, Komisurak B, Ediner H, Feder H, Siegel A (1980) Differential fornix ablations and the circadian rhythmicity of adrenal corticosterone secretion. Brain Res 195:373-380.

Hartley L, Roger R, Nicolosi R, Hartley T (1984) Blood pressure values in Macaca fascicularis. J Med Primatol 13:183-189.

Herman J, Schafer M, Young E, Thompson R, Douglass J, Akil H, Watson S (1989a) Evidence for hippocampal regulation of neuroendocrine neurons of the hypothalamo-pituitary-adrenocortical axis. J Neurosci 9:3072-3077.

Herman J, Young E, Savina A, Watson S (1989b) Hippocampalhypothalamic circuits mediating tonic inhibition of the hypothalamopituitary-adrenocortical axis. Soc Neurosci Abstr 15:58.6.

Insausti R, Amaral DG, Cowan WM (1987) The entorhinal cortex of the monkey. II. Cortical afferents. J Comp Neurol 264:356-395.

Kant G, Meyerhoff J, Jarrad L (1984) Biochemical indices of reactivity and habituation in rats with hippocampal lesions. Pharmacol Biochem Behav 20:793-798.

Keller-Wood M, Dallman M (1984) Corticosteroid inhibition of ACTH secretion. Endocrinol Rev 5:1-24.

Kim C., Kim C (1961) Effect of partial hippocampal resection on stress mechanisms in rats. Am J Physiol 201:337-343.

Knigge K, Hays M (1963) Evidence for inhibitive role of hippocampus in neural regulation of ACTH release. Proc Soc Exp Biol Med 114: $67-71$.

Kovacs K, Kiss J, Makara G (1986) Glucocorticoid implants around the hypothalamic paraventricular nucleus prevent the increase of corticotropin-releasing factor and arginine vasopressin immunostaining induced by adrenalectomy. Neuroendocrinology 44:22-30.

Krey L, Lu K, Butler W, Hotchkiss J, Piva F, Knobil E (1975) Surgical disconnections of the medial basal hypothalamus and pituitary function in the rhesus monkey. II. GH and cortisol secretion. Endocrinology 96:1088-1096.

Mahut M (1972) A selective spatial deficit in monkeys after transection of the fornix. Neuropsychologia 10:65-74.

Mandell A, Chapman L, Rand R, Water R (1963) Plasma corticosteroids: changes in concentration after stimulation of hippocampus and amygdala. Science 139:1212-1214.

Margarinos A, Somoza G, De Nicola A (1987) Glucocorticoid negative feedback and glucocorticoid receptors after hippocampectomy in rats. Horm Metab Res 19:105-110.

Moberg G, Scapagnini U, de Groot J, Ganong W (1971) Effect of sectioning the fornix on diurnal fluctuation in plasma corticosterone levels in the rat. Neuroendocrinology 7:11-18.

Regestein Q, Jackson W, Peterson H (1986) Effects of various hippocampal lesions on monkey plasma cortisol levels in two experimental conditions. Behav Neural Biol 45:329-341.

Sapolsky R (1989) The adrenocortical axis. In: Handbook of the biology of aging, 3d ed (Schneider E, Rowe J, eds), pp 330-348. New York: Academic.

Sapolsky R, Plotsky P (1990) Hypercortisolism and its possible neural bases. Biol Psychiatry 27:937-952.

Sapolsky R, Krey L, McEwen B (1984) Glucocorticoid-sensitive hippocampal neurons are involved in terminating the adrenocortical stress response. Proc Natl Acad Sci USA 81:6174-6178.

Sapolsky R, Armanini M, Sutton S, Plotsky P (1989) Elevation of 
hypophysial portal concentrations of adrenocorticotropin secretagogues after fornix transection. Endocrinology 125:2881-2887.

Sapolsky R, Armanini M, Packan D, Sutton S, Plotsky P (1990) Glucocorticoid feedback inhibition of adrenocorticotropic hormone secretagogue release: relationship to corticosteroid receptor occupancy in various limbic sites. Neuroendocrinology 51:328-336.

Szabo J, Cowan W (1984) A stereotaxic atlas of the brain of the cynomolgus monkey (Macaca fascicularis). J Comp Neurol 222:265300.

Wilson M (1975) Effect of hippocampectomy on dexamethasone suppression of corticosteroid-sensitive stress responses. Anat Record 181: $511-517$.

Wilson M, Greer M, Roberts L (1980) Hippocampal inhibition of pituitary-adrenocortical function in female rats. Brain Res 197:433439.

Zola-Morgan S, Squire L (1990) The primate hippocampal formation: evidence for a time-limited role in memory storage. Science 250:288290.
Zola-Morgan S, Squire L, Amaral D (1989a) Lesions of the hippocampal formation but not lesions of the fornix or the mammillary nuclei produce long-lasting memory impairment in monkeys. J Neurosci 9:898-913.

Zola-Morgan S, Squire L, Amaral D (1989b) Lesions of the amygdala that spare adjacent cortical regions do not impair memory or exacerbate the impairment following lesions of the hippocampal formation. J Neurosci 9:1922-1936.

Zola-Morgan S, Squire L, Amaral D, Suzuki W (1989c) Lesions of perirhinal and parahippocampal cortex that spare the amygdala and hippocampal formation produce severe memory impairment. J Neurosci 9:4335-4370.

Zola-Morgan S, Squire LR, Alvarez-Royo P, Clower RP (1991) Independence of memory functions and emotional behavior: separate contributions of the hippocampal formation and the amygdala. Hippocampus 1:207-220. 